\title{
Building irregularity issues and architectural design in seismic areas
}

\author{
Valerio Alecci, Mario De Stefano \\ University of Florence, Italy \\ valerio.alecci@unifi.it, bttp:/ /orcid.org/0000-0002-8143-7102 \\ mario.destefano@unifi.it,bttp://orcid.org/0000-0001-6077-3732
}

\begin{abstract}
When designing buildings in seismic areas, choices of the architectural designer heavily influences seismic structural performances. Namely, building morphology may lead to complex seismic responses as it occurs when building plan and elevation become irregular. Typical irregularities are due to architectural, functional and distribution constraints, thus leading to plan or vertical or combined plan/vertical irregularities. A frequent plan-wise irregularity arises when earthquake resistant structures, such as cores and shear walls, are concentrated on one side of the building plan, while vertical irregularity often arises from the presence of soft stories especially located at the ground level or, less frequently, at an intermediate level.

In the last decades, some trends in architectural design, such as Deconstructivism and other contemporary theories, worked in pursuing architectural solutions based on the concept of "deconstruction" in place of "construction", favoring non-rigid schemes, non-regular shapes and, more generally, avoiding geometric rules and classical canons of symmetry and regularity.

In this paper the above issues are investigated with the goal of assessing effects of irregularity conditions, introduced by the architectural design, on the building seismic performances with the aim at not forbidding the designer ambitions but at making him aware of the effects of his architectural choices.
\end{abstract}

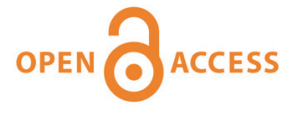

Citation: Alecci, V., De Stefano, M., Building irregularity issues and architectural design in seismic areas, Frattura ed Integrità Strutturale, 47 (2019) 161-168.

Received: 22.08 .2018

Accepted: 20.11.2018

Published: 01.01.2019

Copyright: (C) 2019 This is an open access article under the terms of the CC-BY 4.0, which permits unrestricted use, distribution, and reproduction in any medium, provided the original author and source are credited.

KEYwORDS. Architectural design; Seismic areas; Building irregularity.

\section{INTRODUCTION}

S eismic events of recent decades showed the high vulnerability of irregular buildings. Perfect regularity is an idealization that rarely occurs in new as well as in existing buildings; in turn, the concept of irregularity itself is a "fuzzy" one. Structural irregularities may vary dramatically in their nature and, in principle, are very difficult to define. Definition by Codes refers to the distribution of mass, strength and stiffness, both in plan and in elevation. 
Plan irregularity is characterized by uneven plan distribution of earthquake-resistant structures or masses; vertical irregularity is due to mass, stiffness or strength discontinuities along the building height. Plan and vertical irregularities result in seismic over-demand into specific structures/elements which can lead to their early collapse, while not allowing the entire building structure to exploit its full seismic capacity. In fact, irregularity is one of the most frequent sources of severe damage during earthquake [1]. In 1985, during the earthquake of Mexico City, $42 \%$ of damaged or collapsed structures were corner buildings. Furthermore, many buildings failed in torsion due to asymmetric layout of masonry walls [2]. In the last decades, several studies on the design eccentricity were carried out [3-13]. Building irregularity - unknown concept in the classical and post-classical architecture - became a particularly widespread condition in postmodern and rational architecture. In fact, the famous "five points" of Le Corbusier's architecture generated, for many decades, highly irregular buildings, characterized by free facades, soft stories with slim columns (pilotis), alternating to fully closed or/and opened floor plans, long strips of ribbon windows (and consequent short columns), etc. Otherwise, in the more remote past, wonderful "regular" buildings were built, based on obvious structural and constructive assumptions. In that period, architect and engineer coexisted and their contribution to the final project was perfectly integrated. In fact, in the past, a unique technician, combining creativity and structural knowledge, designed buildings with structural rigor but also expressing his own stylistic will. This condition, which allow architectural and structural issues to be perfectly integrated, played a crucial role for optimizing the final project. This kind of architecture/structure integration, desirable for the success of the project, is strictly necessary when designing in seismic zone, where the lack of architecture/structure integration can involve heavy losses in terms of human lives.

In the last decades, the apparent rigor (more from an architectural than structural point of view, as we highlighted above) of postmodernist movements involved a sort of compositional anarchy that Rob Krier defined "the confusion in today's art of building" and whose deconstructivist architecture is the maximum expression. Deconstructivism worked in pursuing architectural solutions based on the concept of "deconstruction" in place of "construction", favoring non-rigid schemes, non-regular shapes and, more generally, avoiding geometric rules and classical canons of symmetry and regularity. The result of this philosophy is the growing proliferation of aesthetically spectacular buildings, with audacious shapes and impressive dimensions, supported by a clear propensity of contractors and funders to design and realize buildings outside the traditional and classical rules, gaining a "status symbol function" and getting a positive impact on their brand image.

In this contest, it is not possible (and really desirable) to prevent the design of irregular buildings while it has to be pursued that designers know the consequences of their architectural design on a seismic and, more generally, structural field. The architectural designer would achieve a "seismic" training, with the aim at not forbidding his ambitions but at making him aware of the effects of his architectural choices.

\section{STRUCTURAL IRREGULARITY CAUSES}

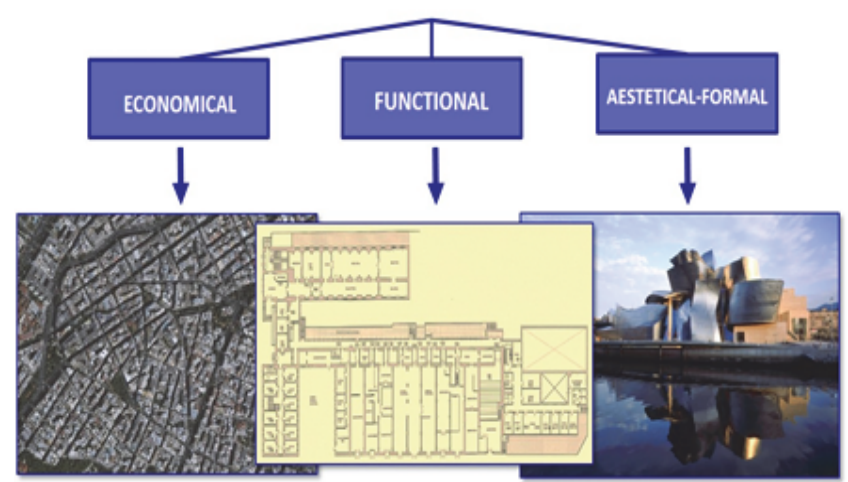

Figure 1: Causes of structural irregularity.

\section{STRUCTURAL IRREGULARITY}

$\mathrm{T}$ he seismic vulnerabilities of a building depend on the morphological and structural condition and on the constructive details. The morphological irregularity is prodromal of structural irregularity and it is due to three main factors: economical, functional and aesthetical-formal (Fig. 1). An economical factor exists because, especially in densely populated urban areas, contractors try to fully exploit the available space in order to obtain the 
maximum economical return; a functional factor exists because the buildings are often organized to have parts with a particular orientation also for better enlighten the different spaces; finally, the aesthetical-formal factor depends on the new architectural trends (as better described in the next paragraph).

Plan irregularity is characterized by uneven plan distribution of earthquake resistant vertical structures and/or of masses; it results in a dangerous torsional behavior consisting of large floor rotations. A close relationship between mass and stiffness plan distribution reduces eccentricity between mass center CM and rigidity center CR, thus resulting in a regular, mainly translational behavior of the building (Fig. 2).
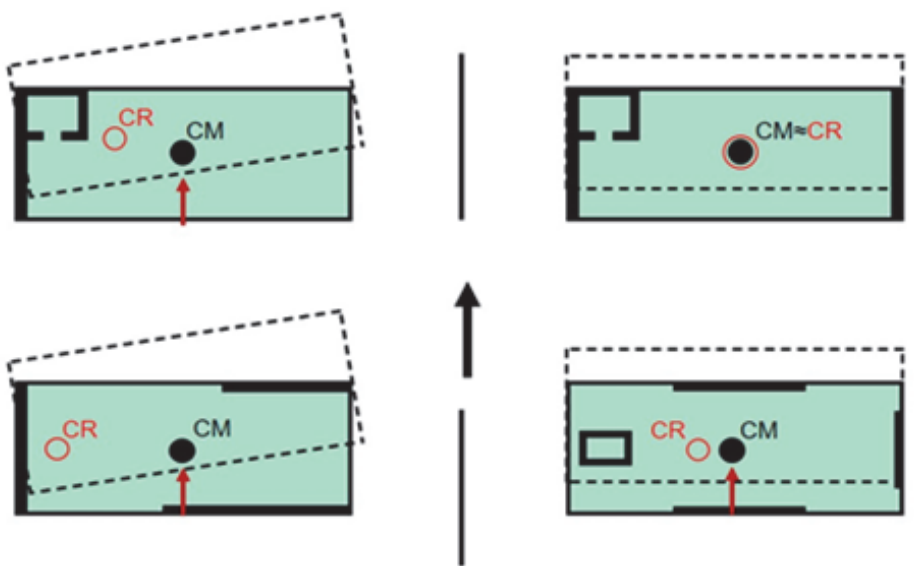

Figure 2: Plan irregularity (on the left) and regularity (on the right).

Plan irregularity is due to a non-symmetrical plan, resulting from a particular functional distribution of the spaces which leads to concentrate stiffness and/or strength on one side of the building plan (stiff side) compared to the other side (flexible side). It may also be due to mass concentration on one side of the building, which becomes the flexible side. In case of seismic actions, building response is characterized by floor rotations (torsional behavior) with increase ductility demands on structural elements often leading to very severe damage or collapse.

Vertical irregularity is due to sudden variations in mass, stiffness (and strength) along the building height, which result in formation of soft/weak storeys where an earlier collapse can develop due to concentration in member forces and ductility demands (Fig. 3).

It can be very common, in contemporary buildings, that layouts of different levels develop as distinct entities in which even structural elements can change in size, consistency, position. This can occur because of changes in the use of a single level or due to the will of the designer to formally differentiate the façade (facades with large openings alternate to fully "closed" portions). Both plan and vertical irregularities (Figg. 4-5) do not allow uniform damage distribution and, therefore, strength and ductility resources of the entire structure cannot be fully exploited. Building codes, such as Eurocodes and the Italian NTC, penalize design of buildings classified as irregular by prescribing larger design forces.
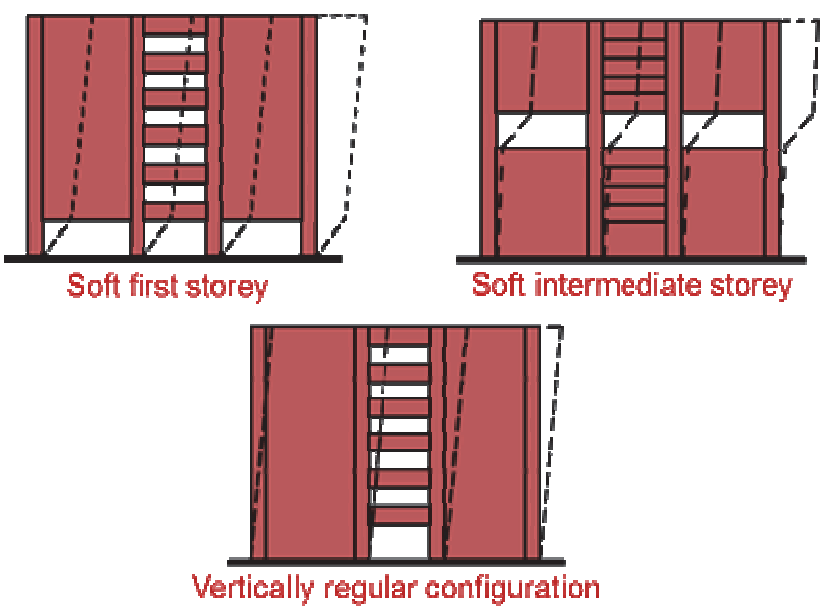

Figure 3: Vertically irregular (above) and regular (below) configurations. 


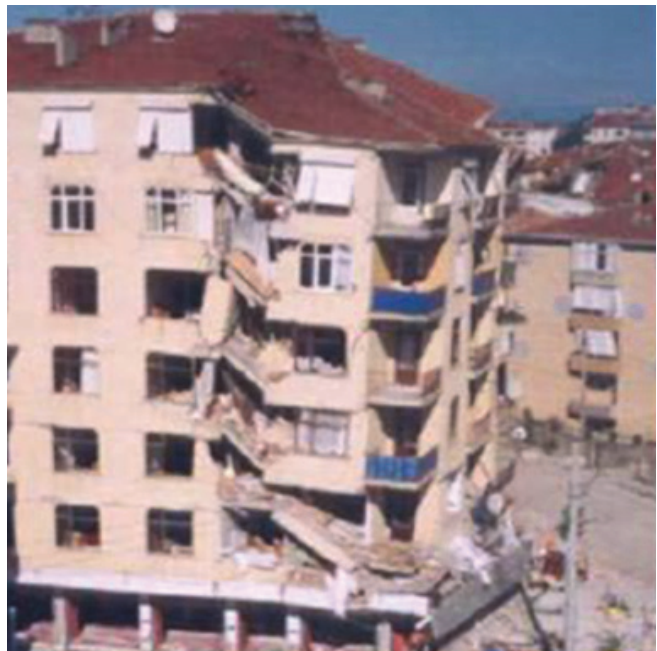

Figure 4: Plan irregularity (Kokaeli, Turkey, 1999).

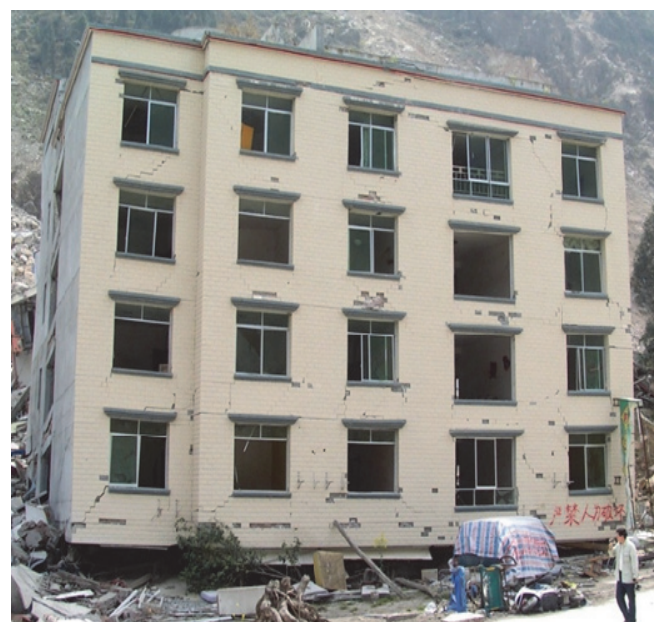

Figure 5: Vertical irregularity (Sichuan, China, 2008).

\section{DECONTRUCTIVIST TRENDS IN CONTEMPORARY ARCHITECTURE} he term "deconstructivist architecture" appears for the first time in 1988, at the exhibition organized by Philip
Johnson and Mark Wigley at the Museum of Modern Art (MoMA) in New York.
Deconstructivism immediately appeared as opposite to the rationality of Postmodernism, Functionalism,
Structuralism and also Eclecticism (in fact, Eclectism is the combination of different materials and styles, but maintaining an architectural scheme still strongly dependent on structural requirements). Deconstructivist architecture represents the overcoming of highly celebrated theories - based on expressions like "form follows function", "purity of form", "truth to material", etc. - and of the philosophy of architects like Le Corbusier, Wright, Mies Van Der Rohe, Michelucci.

Deconstructivism is characterized by an absence of harmony, continuity, or symmetry. Deconstructivist architectures have an unstable geometry, sudden cuts in architectural and structural continuity, deformed volumes, asymmetry, unrecognizability of structural elements. Theoretical base of deconstructivist architecture is the philosophy of the French philosopher Jacques Derrida and, in particular, his concept of "différance". Extending the Heidegger's theory of the difficulty of Being, Derrida recognizes the indefinability of the identity of Being as it preserves an intrinsic "différance". Derrida had a significant influence upon the humanities and social sciences, including literature, law, anthropology, historiography, applied linguistics, psychoanalysis, political theory, ethics, aesthetics, hermeneutics, architecture (in the form of deconstructivism), music.

Derrida's philosophy influenced the Deconstructivism's fathers who exhibited their projects at the MoMA in 1988: Daniel Libeskind, Zaha Hadid, Frank O. Gehry, Rem Koolhaas, Peter Eisenman, Bernard Tschumi. They designed always rejecting the principles of Vitruvian geometry and harmony which Perroult transformed into firmitas, utilitas venustas triad.

In the first book of Vitruvius" treatise "De Architectura", is reported: "All buildings must have solidity, utility and beauty. They will have solidity when the foundations, constructed with materials chosen with care and without greed, will rest deeply and firmly on the ground; utility when the distribution of the interior space of each building will be correct and of practical use; beauty, when the aspect of the work will be pleasant for the harmonious proportion of the parts obtained with the accurately calculated symmetry".

Conversely, in the book "Line of fire" of Daniel Libeskind [14] is reported: "(The Vitruvian Principles) were extended beyond the Roman world, beyond the West, to the Islamic and Indian architecture and, through the European Renaissance, they come to modernity and to the contemporary and globalized world. With their deference to the right angle and the correct way to build, with their care for the geometric order, the symmetry and the rigid proportions, the Ten Books became a sort of emblem of what was codified and institutionalized with the name of Architecture".

Libeskind reflects on "the liberation of architecture from Vitruvio's diktat", proposing a new architecture not depending on geometric rules but on music, astronomy, graphology, theater and art. This philosophy is the crucial base of his projects and buildings: the Berlin Jewish Museum (Fig. 6) inspired by the music of Arnold Schönberg, the new Ground Zero and the Warsaw Tower drawn up following the Sun's motion trajectory, the Las Vegas City Center (Fig. 7) inspired 
by xenomorphic crystals, the Jewish Museum of San Francisco drawn following the Jewish letters, the Piazza Italia for the Expo of Milan inspired by the paintings by Giuseppe Arcimboldo.

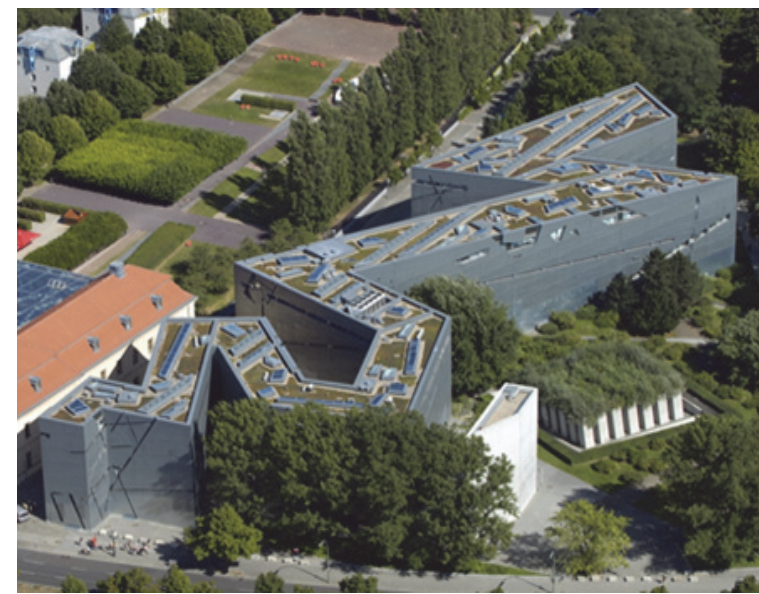

Figure 6: Berlin Jewish Museum

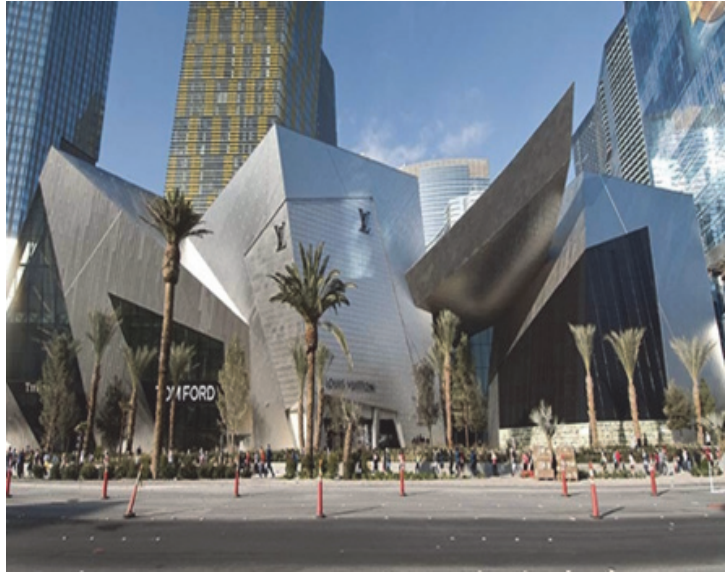

Figure 7: Las Vegas city center

"The classicist architect" - is reported in the monograph on Zaha Hadid directed by Bruno Zevi [15] - "does not put any of his own inspiration when designing, he only applies pre-established codes. Conversely, the "différance" and the deconstruction, are "iconoclasts": no rigid codes can regulate it. "Deconstruction" doesn't generate anonymous buildings, where the designer replicates geometric and structural code requirements and historicized typological schemes. It generates indefinite, confused, transformable spaces". The historian Davide De Sessa defines the Hadid's buildings as "medieval agglomerations made of additions, [...] contrasts between the different levels, anti-geometries" (Fig. 8). Zaha Hadid, like other contemporary architects, "has no truck with typologies, applied orders, implied assumptions of gravity [...], she aims at being liberated from the past and from the constraints of physical laws" [16]. Then, Vitruvian triad is transformed into a sort of "deconstructivist triad", based on the immateriality of the walls, on the anti-gravitational and anti-Cartesian will, on the manipulation of structures. The complex joints in Peter Eisenman's projects, the confusion of the signs in Bernard Tschumi's architecture, the Cubist philosophy of Frank O. Gehry, fully embody these concepts.

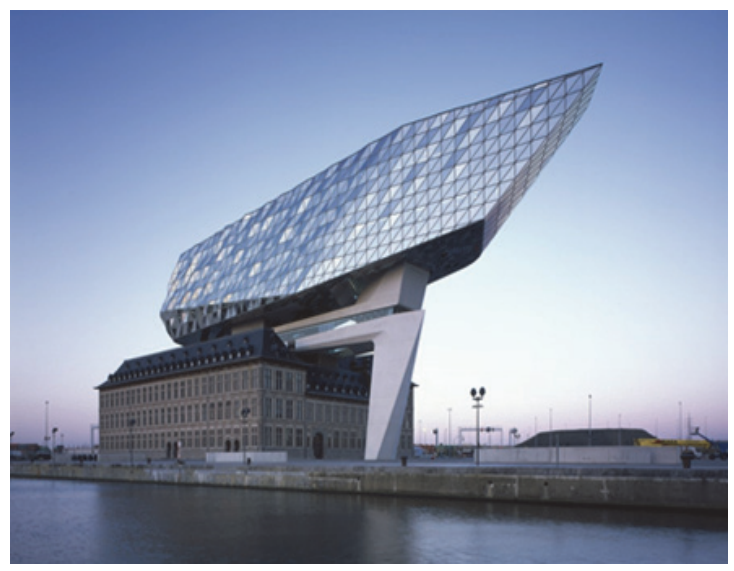

Figure 8: Antwerp Port Authority.

In all of their projects, the manipulation of the building structure is evident. The structural mesh is not detectable, it appears like a part no longer necessary for supporting the construction, a simple figurative game useful to make spaces more enjoyable. "Gehry's architecture is a challenge to common sense", is reported in a monograph of Mildred Friedman [17] dedicated to the Gehry's projects. Gehry's buildings would be defined like "architectural sculptures" than simply like "buildings": Guggenheim Museum of Bilbao (Fig. 9) or the Nationale-Nederlanden Building of Prague (Fig. 10), are today considered great "sculptures" more than architectural buildings. 


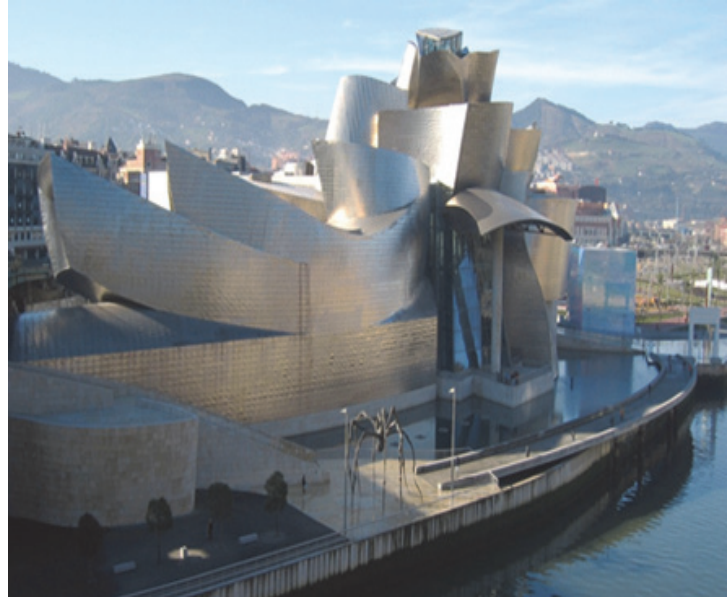

Figure 9: Guggenheim Museum, Bilbao

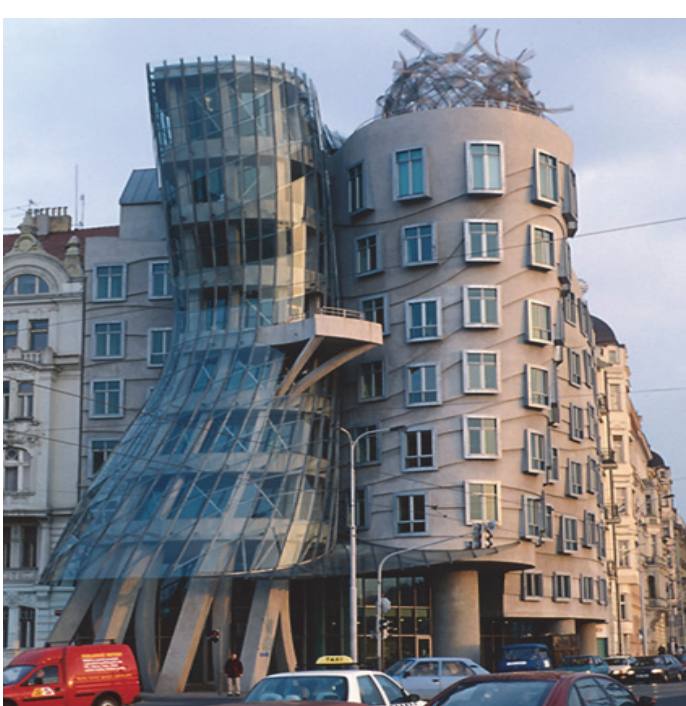

Figure 10: Nationale-Nederlanden Building, Prague

Nowadays, structural architects are increasingly becoming architects/artists who reject the written rules and the structural grids, giving space to creativity, dreams, free inspiration. This cultural trend inevitably influences the new master architects, the young generation of architects, the architectural Schools and Associations which enhance the expressiveness of architectural and structural designers but, at the same time, represents a sort of challenge that architectural designers can overcome if equipped with a solid structural and seismic background. They must know irregularity conditions, their relations with seismic loads and how to mitigate their effects. They must have a threedimensional view of the structural and seismic issues (and not just plane) evaluating the opportunity to apply the simplifications that several calculation methods assume (rigid diaphragm, uniform seismic action, etc.), also performing an additional evaluation in the design stage of some effects which usually are secondary in ordinary buildings, such as torsional moments on individual structural elements, P-Delta effects, etc.

\section{ANALYSIS METHODS OF IRREGULAR STRUCTURES}

$\mathrm{S}$ eismic behavior of irregular structures is usually investigated by single-storey models. Although single-storey models represent the most extreme idealization of plan irregular buildings, they still attract many researchers, as they remain adequate to obtain general information on torsional behavior of asymmetric buildings, particularly from a qualitative point of view.

They have been widely used in the past also due to their capability of clarifying the influence of the governing parameters and derive effective design criteria. However, in recent years multi-storey building models have been used to study more realistically inelastic earthquake response of asymmetric buildings due, firstly, to the shortcomings of one-storey models in predicting torsional behavior of real structures and, secondly, for the development of powerful computational tools able to make extensive and refined numerical analyses of 3D multi-storey building structures.

An accurate prediction of seismic behavior of irregular structures cannot be done by applying a standard Non-linear Static Procedure (NSP) because, in virtue of an uneven plan displacement demand, one target displacement is not sufficient and an evaluation of the amplification of displacement demand due to torsional effect is necessary. Furthermore, no allowances are considered for dynamic effects of lateral-torsional coupling and large uncertainties remain when results obtained from independent pushover analysis in the two horizontal directions are combined.

Nowadays, the main approach available in literature to adapt standard NSPs for plan-irregular structures is represented by different displacement amplification methods. One such method, proposed by Fajfar et al. [18], considers to properly including torsional effects combining the results obtained by pushover analysis of a 3D structural model, based on the N2 method, with the results from a linear dynamic (spectral) analysis. The N2 method controls the target displacements and distribution of deformations along the height of the building, whereas the linear dynamic analysis is used to define the 
torsional amplifications of lateral displacements. The elastic amplifications of lateral displacements obtained by modal analysis are conservative with respect to the inelastic ones. Tests on case study buildings gave promising results [19-20]. The assumption of the conservativeness of the elastic envelope appears to be valid for torsionally flexible and moderately torsionally stiff (framed) building structures. On the contrary, it does not hold true for very torsionally stiff structures, such as shear-walled buildings [21]. Another method, proposed by Ghersi et al., [22], is based on modal analysis involving the definition of corrective eccentricities used to determine the application points of the load vectors, on either sides of the CM so as to obtain an envelope of plan distribution of maximum displacements. Corrective eccentricities have been calibrated from response of a one-storey building while their application to multistory buildings requires complex parameters definition.

\section{FINAL CONSIDERATIONS}

1 rchitectural design in seismic areas is the first and fundamental step to guarantee good seismic performance. Architectural designer must be aware that his choices of building morphology, plan and vertical layout of resisting structures, member tentative dimensions, have a profound impact on the behavior under seismic actions. This paper has focused on the effects of irregularity conditions resulting from architectural design. It is demonstrated that irregularities, arising from economical, functional and aesthetical/formal requirements, cannot be prohibited; however, architectural designer must know irregularity conditions, their outcome on seismic response and how to mitigate their effects.

\section{ACKNOWLEDGEMENTS}

he financial support of ReLUIS through the Progetto Esecutivo Convenzione DPC/ReLUIS 2017 - PR2 Strutture in cemento armato - is gratefully acknowledged.

\section{REFERENCES}

[1] De Stefano, M. and Pintucchi, B. (2008). A review of research on seismic behavior of irregular building structures since 2002, Bulletin of earthquake Engineering, 6(2), pp. 285-308.

[2] Rosenlueth, E. and Meli, R. (1986). The 1985 Earthquake: Causes and effects in Mexico City, Concrete International, 8(5), pp. 23-34.

[3] Tso, W. K. (1990). Static Eccentricity Concept for Torsional Moment Estimations, Journal of Structural Engineering, 116(5) pp. 1199-1212.

[4] Chopra, A. K. and Goel, R. K. (1991). Evaluation of torsional provisions in seismic codes, Journal of Structural Engineering, 117(12), pp. 3762-3782.

[5] De Stefano, M. Faella, G. and Ramasco, R. (1993). Inelastic response and design criteria of plan-wise asymmetric systems, Earthquake Engineering and Structural Dynamics, 22(3), pp. 245-259.

[6] Chandler, A. Correnza, J. C. and Huchinson, G. L. (1995). Influence of accidental eccentricity on inelastic seismic torsional effects in buildings, Engineering Structures, 17(3), pp. 167-178.

[7] De Stefano, M. and Rutenberg, A. (1997). A comparison of the present SEAOC/UBC torsional provisions with the old ones, Engineering Structures, 19(8), pp. 655-664.

[8] Foraboschi, P. (2016). The central role played by structural design in enabling the construction of buildings that advanced and revolutionized architecture. Construction and Building Materials, 114, pp. 956-976.

[9] Foraboschi, P. (2016). Versatility of steel in correcting construction deficiencies and in seismic retrofitting of RC buildings. Journal of Building Engineering, 8, pp. 107-122.

[10] Foraboschi, P. 2016. Structural layout that takes full advantage of the capabilities and opportunities afforded by twoway RC floors, coupled with the selection of the best technique, to avoid serviceability failures. Engineering Failure Analysis, 70, pp. 387-418.

[11] Sassu, M. Puppio, M. L. Mannari, E. (2017). Seismic Reinforcement of a R.C. School Structure with Strength Irregularities throughout External Bracing Walls, Buildings, 7(58). DOI:10.3390/buildings7030058. MDPI. 
[12] Puppio, M. L. Pellegrino, M. Giresini, L. Sassu, M. (2017). Effect of Material Variability and Mechanical Eccentricity on the Seismic Vulnerability Assessment of Reinforced Concrete Buildings, Buildings, 7(66). DOI:10.3390/buildings7030066. MDPI.

[13] Bonannini E., Cinotti, M. Puppio, M. L. Sassu, M. (2017). Seismic response of a stock of social housings in Italy with R.C. and masonry materials, Advances in Engineering Research (AER), Second International Conference on Mechanics, Materials and Structural Engineering (ICMMSE 2017). Atlantis Press (102 - 285).

[14] Libeskind, D. (2014). La linea del fuoco - scritti, disegni, machine, Macerata, Quodlibet s.r.l.

[15] Zevi, B. and De Sessa, D. (1996). Zaha Hadid - Eleganze dissonanti (1st Ed.), Torino, Testo e Immagine s.r.l.

[16] Betsky, A. (1998). Zaha Hadid - The Complete Buildings and Projects, London, Thames and Hudson.

[17] Friedman, M. (2000). Frank O. Gehry - architettura + sviluppo, New York, Rizzoli International Publication Inc.

[18] Fajfar, P. Marusic, D. and Perus, I. (2005). The extension of the N2 method to asymmetric buildings, Proceedings of the 4th European workshop on the seismic behavior of irregular and complex structures, cd-rom, Thessaloniki, Greece.

[19] Bhatt, C. and Bento, R. (2012). Comparison of Nonlinear Static Methods for the Seismic Assessment of Plan Irregular Frame Buildings with Non Seismic Details, Journal of Earthquake Engineering, 16, pp. 15-39.

[20] Bosco, M. Ghersi, A. Marino, E.M. and Rossi, P.P. (2013). Comparison of nonlinear static methods for the assessment of asymmetric buildings, Bulletin of earthquake Engineering, 11(6), pp. 2287-2308.

[21] De Stefano, M. and Pintucchi, B. (2010). Predicting torsion-induced lateral displacements for pushover analysis: influence of torsional system characteristics, Earthquake Engineering and Structural Dynamics, 39(12), pp. 13691394.

[22] Ghersi, A. Marino, E.M. and Rossi, P.P. (2007). Static versus modal analysis: influence on inelastic response of multistorey asymmetric buildings, Bulletin of earthquake Engineering, 5(4), pp. 511-532. 